International Journal of Engineering \& Technology, $7(4.20)(2018) 485-490$
Snternational Journal of Engineering \& Technology
SPC
Website www.sciencepubco.com/index.php/IJET
Research paper

\title{
Modified Strut Effectiveness Factor for FRP-Reinforced Concrete Deep Beams
}

\author{
Ammar N. Hanoon", *, Salah R. Al Zaidee², Qais Sahib Banyhussan³, Ali A. Abdulhameed ${ }^{1}$ \\ ${ }^{I}$ Department of Reconstruction and Projects, University of Baghdad, Iraq \\ 2Department of Civil Engineering, University of Baghdad, Iraq \\ ${ }^{3}$ Department of Highway and Transportation Engineering, Al-Mustansiriya University, Baghdad, Iraq \\ ${ }^{I}$ Department of Reconstruction and Projects, University of Baghdad, Iraq \\ *Corresponding author E-mail: anh@uobaghdad.edu.iq
}

\begin{abstract}
A few examinations have endeavored to assess a definitive shear quality of a fiber fortified polymer (FRP)- strengthened solid shallow shafts. Be that as it may, need data announced for examining the solid profound pillars strengthened with FRP bars. The majority of these investigations don't think about the blend of the rigidity of both FRP support and cement. This examination builds up a basic swagger adequacy factor model to evaluate the referenced issue. Two sorts of disappointment modes; concrete part and pulverizing disappointment modes were examined. Protection from corner to corner part is chiefly given by the longitudinal FRP support, steel shear fortification, and cement rigidity. The proposed model has been confirmed utilizing an aggregate of 45 databases gathered from writing. Results show that the proposed model can evaluate a definitive shear quality. Structure of trial (DOE) programming was used to examine the impact of different parameter esteems on a definitive shear quality limit. The outcomes demonstrate that the shear range to powerful profundity proportion has the most astounding impact contrasted and alternate parameters.
\end{abstract}

Keywords: Concrete deep beams; Strut effectiveness factor; Strut-and-tie model; ultimate strength; FRP bars, DOE.

\section{Introduction}

Reinforced concrete (RC) is used usually as a construction material due to the availability of the raw material and flexibility in producing various shapes, color, and sizes. However, the major issue with the concrete material is its durability when used in harsh weather conditions. Corrosion of steel reinforcement is the major defects that affect durability, performance and service life of reinforced concrete structures. RC structures that located in marine environments are affected by corrosion due to high salt content and thus, require an expensive maintenance. In recent times, an innovative approach has been attempted to reduce the corrosion effects in RC structures by using fiber-reinforced polymer (FRP) as an alternative material. This is because FRP materials are non credible in nature and they have a high strength-to-weight ratio making attractive materials for use as reinforcement.

FRP reinforcements in concrete have been investigated in many research programs. The flexural and shear behavior of FRPreinforced concrete shallow beams has been conducted. However, in deep beams reinforced with FRP bars have not yet been fully explored. FRP and steel reinforcements differ in many aspects due to the variability in their mechanical properties such as the modulus of elasticity, the shear strength etc.

The behavior of structural (RC) members is classified into Bernoulli regions (B-region) and discontinuity region (D-region). Bregion assumes a linear strain distribution. On the other hand, the D-region does not develop a linear strain distribution and, hence, the design of RC members under this category cannot be conducted using the principles of stress analysis that based on the B- region assumption (Foster \& Gilbert, 1996). Approaches based on semi-empirical design, stress analysis design, and strut-and-tie models (STM) are being considered in various codes of practice for designing a D-regions (Foster \& Gilbert, 1996).

According to ACI building code (ACI318-14, 2014), STM model should be used to design steel reinforced concrete deep beams due to its ability to accommodate the non-traditional force distribution in D-regions, as an alternative to base on an empirical formula. Modification of design factors is required to apply this model to the FRP reinforced concrete deep beams due to the difference between the steel and FRP reinforcement properties.

There is a lot of research works on the shear behavior of FRP reinforced slender beams having a shear span-to-depth ratio greater than 2.5 , also, there are many design models proposed that provide estimates with reasonable accuracy on shear strengths of FRP RC beams (El-Sayed, El-Salakawy, \& Benmokrane, 2006a, 2006b; Nehdi, Omeman, \& El-Chabib, 2008; Razaqpur \& Isgor, 2006). Relatively few research works have been achieved to estimate the ultimate shear capacity of FRP-reinforced concrete deep beams. However, the standards design handbook is under development. In STM, a new strut effectiveness factor model for RC deep beam reinforced with FRP bars was suggested within the range of 1.5-2.5 of $a / d$ by (Nehdi, Omeman, and El-Chabib (2008)). In that study, 19 concrete deep beams were produced and tested in that work to determine the strut effectiveness factor as recommended in CSA A23.3, ACI 318 code and AS3600. The main variables were the concrete strength, a/d, types of FRP bars such as CFRP and GFRP and bottom reinforcement ratio. The study was the first to propose strut effectiveness factor for deep beam reinforced with FRP bars. The novelty of that work is a model 
proposed for strut effectiveness factor, however, it is inadequate due to the small number of testing RC deep beams (Nehdi et al., 2008).

According to the aforementioned discussions, this paper aims to propose a new effectiveness factor to be used with the STM in the design of FRP- reinforced concrete deep beams. Unlike the other models, the proposed one takes into account the influence of the concrete and steel reinforcements (longitudinal and shear) tensile strength combination. A modified Mohr-Coulomb is utilized as the failure criterion model. Furthermore, two concrete failure modes are considered in this study, namely, crushing and diagonal splitting failure mode. A parametric analysis has been carried out using design of experiment (DOE) software to study the influence of different geometrical and physical properties on the ultimate shear capacity. The results show that the shear span to effective depth ratio is the most influential parameter for estimating the ultimate shear strength of FRP-reinforced concrete deep beams

\section{Methodology}

\subsection{Strut-and-tie model (STM)}

STM is a promising analytical tool for designing RC structures that minimize complex cases of stress distribution to a set of simple stress trajectories. The STM concept, dated back to early 1900 depends on the truss analogy method and was derived by Mörsch in 1902 for shear design (Victoria, Querin, \& Martí, 2011). The main origin of STM development can be found in ((J Schlaich \& Weischede, 1982), (Jorg Schlaich \& Schafer, 1991; Jorg Schlaich, Shafer, Jennewein, \& KOTSOVOS, 1987)), and all focused on the D-region design philosophy. The flow of force in the cracked region of the concrete area has been carried out using STM Model. Conceptually, STM is a simple design approach that involves different stress limits and conditions on the nodal zones and strut components. These limits are empirically distinct which may be under or over conservative in special cases, though, the stress limits are set to include all the stress conditions.

Representation of powers stream is less demanding with the utilization of the STM display. It is a bracket demonstrate that speaks to all the inner powers and requires no different flexure or shear models as in slim individuals investigated utilizing sectional methodologies. STM is in accordance with the lower bound hypothesis of pliancy, which require just balance conditions to be fulfilled. The lower bound hypothesis expresses that "if the heap has such an extent, to the point that empowers deciding the pressure appropriation that compares to worries inside the yield surface and keeps up interior and outer balance, at that point this heap won't make the body fall" (Nielsen and Cao, 2010). Along these lines, the basic limit evaluated utilizing the methodology is not exactly or equivalent to the real disappointment heap of the structure under thought. The most essential element of the lower bound methodology is its natural conservatism.

\subsection{Proposed swaggers adequacy factor show}

As introduced in Figure 1, hub Compressive, f_2, and Transverse tractable, $f_{-} 1$, stresses are framed in the slanting solid swagger because of the connected load, $V \_n$. Compressive pressure $f \_2$ is made along the bearing between the connected load and the help This pressure causes a conceivable arrangement of solid pulverizing disappointment in the slanting swagger, which must be opposed by the solid compressive quality vf $\mathrm{c}^{\prime}$, where $v$ is the swagger viability factor (CEB-FIP 1993; CSA 1994). Transverse pliable pressure $f_{-} 1$ is produced toward a path opposite to the corner to corner swagger. Subsequently, the profound pillar may flop because of cement part, which can be limited by the longitudinal FRP bars, transverse support, and cement rigidity.

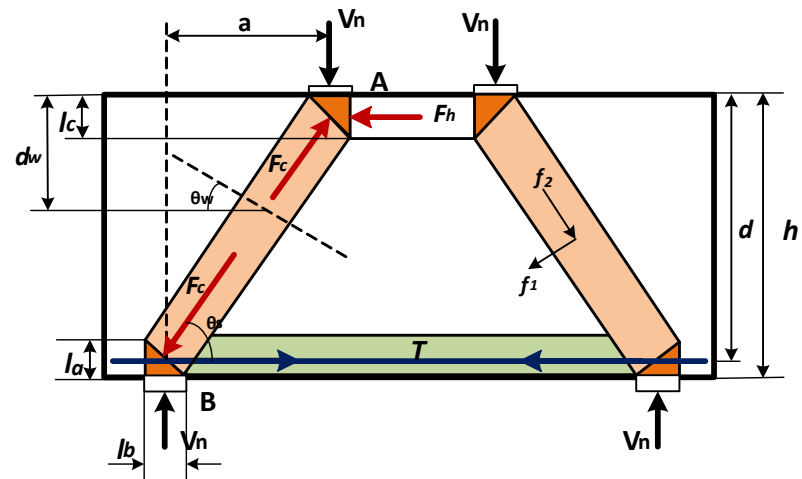

Fig. 1: Strut-and-tie model for simply supported deep beams

Force equilibrium at the bottom nodal zone (B) of the diagonal strut (Fig. 1) are applied through the following equations:

$\sum F_{y}=0 ; \quad F_{c}=\frac{V_{n}}{\sin \theta_{s}}$

$\sum F_{x}=0 ; \quad T=\frac{V_{n}}{\tan \theta_{s}}$

$\theta_{S}$ denotes to the inclined concrete strut angle and it is defined by

$\tan \theta_{s}=\frac{Z_{s}}{a}$

$Z_{s}=h-\frac{l_{a}}{2}-\frac{l_{c}}{2}$

where, $l_{a}$ and $l_{c}$ respectively indicate the top and bottom nodal zone depth (see Fig. 1).

The axial compressive stress $f_{2}$ can be determined from Eq. (1) as follows:

$f_{2}=\frac{F_{c}}{A_{s t r}}=\frac{V_{n}}{A_{s t r} \sin \theta_{s}} \quad$ (compressive)

w

$f_{1}=\frac{k T \sin \theta_{s}}{A_{c} / \sin \theta_{s}}=k P \quad$ (tensile)

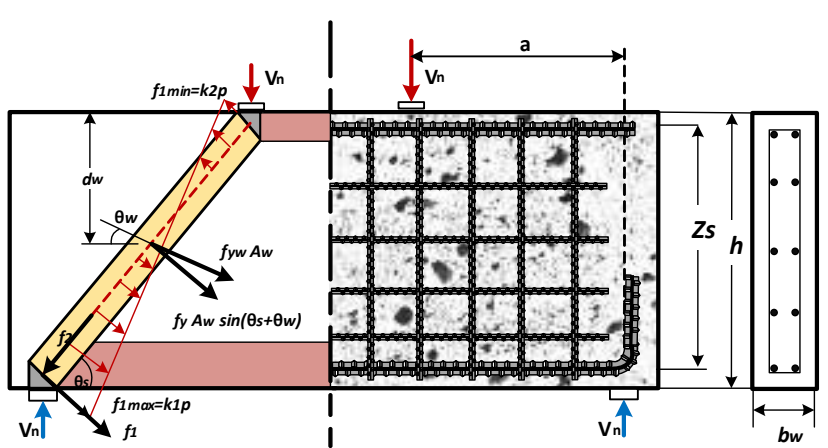

Fig. 2: Determination of Tensile Stress $f_{1}$ at Bottom Nodal Zone

Referring to Fig. 2, the stress distribution factors $\left(k_{1}\right.$ and $\left.k_{2}\right)$ cannot be calculated according to the beam theory, therefore, additional assumptions are necessary. Based on considering the forces equilibrium and ignoring the moment equilibrium, Tan et al. (Tan, Tong, \& Tang, 2001) proposed $k_{1}=2$ and $k_{2}=0$. A value of 2.5 for $\mathrm{k}$ factor was suggested for concrete deep beams under to different loading rates (Hanoon et al., 2016). Furthermore, a value of 2 is proposed for $\mathrm{k}$ factor by considering the CFRP sheet as a strengthening material for RC deep beams (Hanoon et $a l ., 2017 \mathrm{~b}$ ). In the current research, both moment and force equilibrium have been taken into consideration. What's more, it is expected that the pressure dissemination is straight along the solid swagger for effortlessness. As appeared in Fig.2, considering fortifying bars slanted at a point $\theta \mathrm{w}$ from the even and with a vertical separation 
d_w estimated from the shaft best to the convergence of the bar with the essential swagger. From minute balance about the hub, and power harmony in the $f_{-} 1$ course with expecting straight pressure dispersion, $\mathrm{k} \_1$ and $\mathrm{k} \_2$ can be resolved.

$$
\left\{\begin{array}{l}
k_{1}=6 \frac{d_{w}}{Z_{s}}-2 \\
k_{2}=4-6 \frac{d_{w}}{Z_{s}}
\end{array}\right.
$$

The base nodal zone is oppressed into a biaxial strain pressure state, and there is decrease in cement compressive quality because of the softening impact of the ductile pressure. In contrast to different methodologies, this examination proposes a disappointment model at the base nodal zone as a direct intelligent connection somewhere in the range of $\mathrm{f} \_1$ and $\mathrm{f} \_2$, from the altered MohrCoulomb hypothesis (Cook and Youthful, 1999), as clarified in the following area.

\subsubsection{Consideration of Concrete Softening Effect}

Three fundamental strategies, which thought about the solid softening impact under biaxial tension- pressure, have been used. These techniques are recorded in the accompanying:

Standard structure determinations, involving AASHTO, 2012; ACI318-14, 2014; ASCE-ACI445, 1999; CEB-FIP, 1993, that receives the solid quality proficiency factors, which deduced from measurable test outcomes. Be that as it may, a discussion be in surveying these components. Besides, for some explicit conditions, these variables might be finished or thought little of as they are characterized as experimental qualities.

Articulations, for example, $\beta=\mathrm{f}\left(\varepsilon_{-} 1\right)$, are utilized to decide the productivity factors as an element of the foremost strain (CSAS806-02, 2004; Duthinh, 1999; Cultivate and Malik, 2002). This methodology is promising and more precise, yet it is intricate because of the concurrent use of harmony conditions, stressstrain connections, and similarity conditions.

Altered Mohr- Coulomb hypothesis with straight intuitive disappointment criteria by (Tan et al., 2001) has been utilized to represent the immediate impact of softening. Kupfer, Hilsdorf, and Surge (1973) proposed a biaxial tension- pressure foundation utilizing a test approach; this rule is in congruity with test results contrasted and the changed Mohr- Coulomb hypothesis. Along these lines, the relationship of Eq. (7) is utilized in this examination:

$\frac{f_{1}}{f_{t}}+\frac{f_{2}}{f_{c}^{\prime}}=1$

where $f_{1}$ and $f_{2}$ respectively refer to the principal tensile and compressive stresses at the nodal zones, which denote the actual stress state. $f_{c}{ }^{\prime}$ indicates the cylinder concrete compressive strength.

$f_{2} \leq f_{c}{ }^{\prime}$

The denominator term $f_{t}$ in Eq. (7) refers to the combination of the tensile strength contribution of FRP reinforcement bars, and the concrete known by:

$f_{t}=\frac{k A_{F R P} f_{F R P} \sin \theta_{s}}{A_{c} / \sin \theta_{s}}+\frac{2 A_{w} f_{y w} \sin \left(\theta_{s}+\theta_{w}\right)}{A_{c} / \sin \theta_{s}} \frac{d_{w}}{d}+f_{c t}$

where $A_{F R P}$ and $A_{w}$ are refer to the total areas of FRP longitudinal and shear reinforcement; $f_{F R P}$ and $f_{y w}$ are ultimate strengths of FRP reinforcement bars and yield strengths of shear reinforce- ment, respectively, and $f_{c t}$ refers to the concrete tensile strength and is reported by (Tan et al., 2001)

$f_{c t}=0.5 \sqrt{f_{c}^{\prime}}$

For simplicity, the second term in Eq. (9a) can be reduced to $\frac{A_{s v} f_{y w} \sin 2 \theta_{s}}{2 A_{c}}$ or $\frac{A_{s h} f_{y w} \sin ^{2} \theta_{s}}{A_{c}}$, respectively, where $A_{s h}$ and $A_{s v}$ are the total areas of vertical and horizontal web reinforcement within the distance of clear span.

The tensile capacity of longitudinal FRP reinforcement is denoted by the first term in Eq. $(9 a)$ which is derived similar to $f_{1}$ in Eq. (5). However, longitudinal reinforcement, full strength is used instead of $T$. Besides, the longitudinal reinforcement effect $\left(A_{F R P} f_{F R P} \cos \theta_{S}\right)$ in the direction of $f_{2}$ has been neglected for the sake of conservatism and simplicity. Considering beam having small $a / d$ ratio, this factor is insignificant as $\cos \theta_{s}$ approaches zero. If the shear span to effective depth ratio, $a / d$, is reasonably high, the beam may fail due to over tensile stress in the $f_{1}$ direction. In such case, failure is dominated by the first term in Eq. (7), and thus, the term $f_{c}{ }^{\prime}$ has insignificant effect on the ultimate shear capacity. Thus, it is justifiable to disregard the contribution of longitudinal FRP reinforcement to the compressive capacity in the $f_{2}$ direction.

The tensile capacity of the inclined shear reinforcement at an angle $\theta_{w}$ to the horizontal axis is represented in Eq. ( $\left.9 a\right)$ as shown in Fig. 2. Consideration is given to positions and arrangements of web reinforcement in horizontal, vertical, combined or inclined. From the STM geometry, the contribution of the tensile force in the web reinforcement along $f_{1}$ direction is $A_{w} f_{y w} \sin \left(\theta_{s}+\theta_{w}\right)$ and the positional influence factor $d_{w} / d$ (Tong, 1997) is used to take care of different levels of web reinforcement which represents the tensile contribution from concrete.

The following equation (Eq. (10)) can be deduced from the bottom nodal zone when subjected to biaxial compression-compression stress state.

$V_{n} \leq A_{s t r} f_{c}^{\prime} \sin \theta_{s}$

\subsubsection{Strut effectiveness factor derivation}

Many researchers have proposed analytical models that consider the softening effect due to compression in RC cracking under tension-compression stress states (Foster, 1992; Tanapornraweekit, Haritos, \& Mendis, 2010; Vecchio \& Collins, 1986). Based on this proposed STM model, strut effectiveness factor $v$ for concrete (Fig. 3) can be expressed as follows:

$\frac{F_{c}}{A_{s t r}}=v f_{c}^{\prime}$

By Substitute Eqs. (4), (5), and (11) into Eq. (7), the strut effectiveness factor can be found as follows:

$v=\left(1-\frac{k T_{F R P} \sin ^{2} \theta_{s}}{A_{c} f_{t}}\right)$

where $T_{F R P}$, denotes the bottom FRP reinforcement tension force illustrated as $\varepsilon_{F R P} E_{F R P} A_{F R P}$. The contribution of the FRP-tension force, resolved in the direction of the diagonal concrete strut represents the second term in Eq. (12), which reduces the compression force in the strut itself. Through substituting Eq. (9a) in Eq. (12) and utilizing the $T_{F R P}$ and $\varepsilon_{F R P}$ relationship, the effectiveness factor can be generated as follows:

$v=\left(1-\frac{k \varepsilon_{F R P} E_{F R P} A_{F R P} \sin ^{2} \theta_{s}}{A_{c} f_{t}}\right)$ 
where $A_{F R P}$ and $E_{F R P}$ refers to the FRP-bars cross-sectional area and its elastic modulus. $\varepsilon_{F R P}$ denotes the longitudinal FRP reinforcement strain. $\theta_{s}$ denotes the angle of inclination of the strut. As presented in Eqs. (12) and (13), the strut effectiveness factor, $v$, is affected by numerous parameters like, FRP reinforcement ratios, $\rho_{F R P}=A_{F R P} / A_{c}$, concrete tensile strength, $f_{t}$, longitudinal FRP reinforcement strain, $\varepsilon_{F R P}$, and the strut angle, $\theta_{s}$. However, the strut angle, $\theta_{s}$, is the main factor that significantly affects the effectiveness factor $v$.

The nominal shear strength $V_{n}$ can be accounted by substituting Eqs. (12) and (11) into Eq. (1) as follows:

$V_{n}=v A_{s t r} f^{\prime}{ }_{c} \sin \theta_{s}$

It is helpful to take note of that the best nodal zone is under a biaxial compression- pressure state. The creators recommend that the compressive worry toward the inclining swagger at the interface of the best nodal zone to be equivalent or littler than f_c', as showed in Eq. (8). Along these lines, Eq. (14) resistances the pressure disappointment of the best nodal zone because of the intuitive nature among strain and pressure worries in the disappointment rule. It accept that the width of the best nodal zone is in a similar request with that of the base help locale. Consequently, no further alteration is given to the best hub.

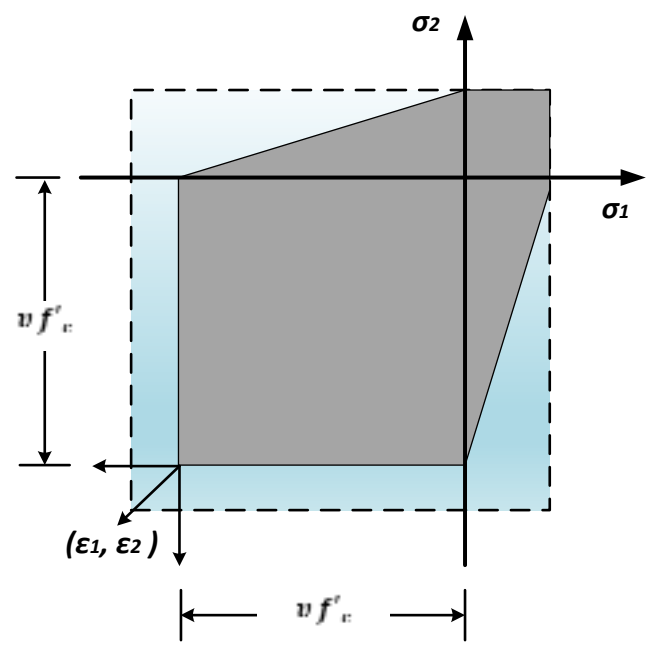

Fig. 3: Modified Coulomb failure criteria.

\subsubsection{STM dimensioning}

The cross-sectional area of the strut, $A_{s t r}$, is calculated from the following:

$A_{s t r}=b_{w}\left(l_{a} \cos \theta_{s}+l_{b} \sin \theta_{s}\right)$

$l_{c}=\frac{V_{n}}{0.85 f_{c}^{\prime} b_{w} \tan \theta_{s}}$

\subsubsection{Data sets and data processing.}

A total of 45 experimental data from various published researches was collected to verify the proposed model (Nehdi et al., 2008; Andermatt, M. F. and Lubell A. S., 2013; FarghalyA. S. and Benmokrane B., 2013; Kim, D. et al., 2014; Latosh, F. A., 2014; Mohamed, K., 2015). The factors selected as inputs included: $(i)$ beam width, $b_{w}$, (ii) shear span-to-depth ratio, $a / d$, (iii) concrete compressive strength, $f_{c}{ }^{\prime}$, (iv) ultimate strength of FRP bars, $f_{F R P}$, (v) longitudinal FRP reinforcement ratio, $\rho_{F R P}$, and (vi) elastic modulus of FRP bars, $E_{F R P}$, as well as an output vector that contains the corresponding ultimate shear strength capacity, $V_{n}$. Table 1 summarizes the beams naming of the collected experimental database.

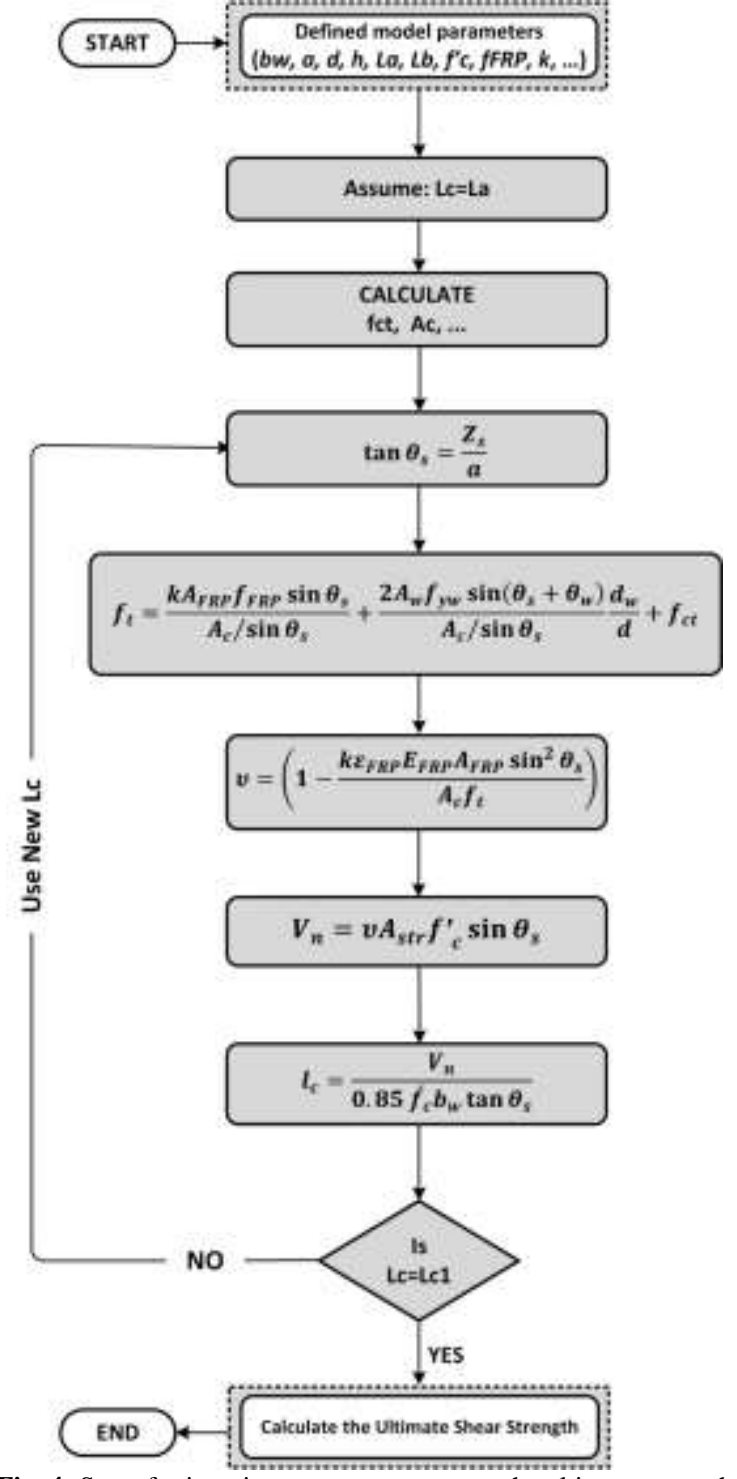

Fig. 4: Steps for iterative process to compute the ultimate strength

Table 1: Beams naming used in the database.

Nehdi, Met al., 2008: CF-B-1, CF-B-1.5, CF-B-2, CF-pl-1.5, CF-pl-2.0, CF-d-250, CF-d-350, CF-f' o-60 F-B-1, F-B-1.5, F-B-2, F-pl-1.5, F-pl-2.0, F-d-250,F-d-350.

Andermatt, M. F. and Lubell A. S., 2013: AIN, A2N, A3N, A4N, BIN, B2N, B3N, B4N, B5N, B6N, C1N, C2N .

Farghaly, A. S. and Benmokrane, B., 2013: G6N8, G8N8, Cl2N3, C12N4.

Kim, D.et al., 2014: A3D9M-1.4, A3D9M-1.7, A3D9M-2.1, A4D9M-1.7, A5D9M-1 7, A3D9S-1 7, A5D9L-1 7, C3D9M-1.4, C3D9M-1.7, C3D9M2.1, C4D9M-1.7, C5D9M-1.7,C5D9L-1.7.

Latosh, F. A., 2014: Al/100, Al/75, A1/50, Al/00, B1.5/100.

Mohamed, K, 2015: G1.47, G1.47H, G1.47V, G1.13H, SG1.13VH

Performance of any model developed using a database is influenced by the sample size and the probability distributions of the variables. The data descriptive statistics are given in Table 2 .

Table 2: Descriptive statistics of the variables used in the model development

\begin{tabular}{llccccc}
\hline Parameter & $\begin{array}{l}B w, \\
m m\end{array}$ & $a / d$ & $\begin{array}{c}f^{\prime} c, \\
M P a\end{array}$ & $\begin{array}{c}f \\
F R P, M P \\
a\end{array}$ & $\rho_{F R P}$ & $\begin{array}{l}E_{F R P}, \\
M P a\end{array}$ \\
\hline $\begin{array}{l}\text { Mean } \\
\text { Standard }\end{array}$ & 220.3 & 1.63 & 39.65 & 1226.5 & $\begin{array}{l}0.0114 \\
2\end{array}$ & 79.32 \\
Error & 9.98 & 0.05 & 1.78 & $\begin{array}{l}74.559 \\
1\end{array}$ & $\begin{array}{l}0.0009 \\
0\end{array}$ & 6.1 \\
Median & 200 & 1.7 & 39.75 & 1180 & $\begin{array}{l}0.0124 \\
1\end{array}$ & 80.7
\end{tabular}




\begin{tabular}{|c|c|c|c|c|c|c|}
\hline Mode & 150 & 1.7 & 26.1 & 1180 & $\begin{array}{l}0.0038 \\
0\end{array}$ & 134 \\
\hline $\begin{array}{l}\text { Standard } \\
\text { Deviation }\end{array}$ & 66.25 & 0.33 & 11.77 & $\begin{array}{l}494.56 \\
91\end{array}$ & $\begin{array}{l}0.0059 \\
4\end{array}$ & 40.44 \\
\hline $\begin{array}{l}\text { Sample Vari- } \\
\text { ance }\end{array}$ & $\begin{array}{l}4388 . \\
65\end{array}$ & $\begin{array}{l}0.11 \\
12\end{array}$ & $\begin{array}{l}138.6 \\
4\end{array}$ & $\begin{array}{l}24459 \\
8.6\end{array}$ & $\begin{array}{l}3.53 \mathrm{E}- \\
05\end{array}$ & 1635.13 \\
\hline Minimum & 150 & 1.07 & 26.1 & 709 & $\begin{array}{l}0.0025 \\
7\end{array}$ & 37.9 \\
\hline Maximum & 310 & 2.33 & 68.5 & 1955.8 & 0.0231 & 144 \\
\hline Sum & 9695 & $\begin{array}{l}71.7 \\
5\end{array}$ & $\begin{array}{l}1744 . \\
6\end{array}$ & $\begin{array}{l}53966 . \\
1\end{array}$ & $\begin{array}{l}0.5024 \\
2\end{array}$ & 3490 \\
\hline
\end{tabular}

Figure 5, that has been generated using DOE software, shows that $a / d$, has the highest effects on the ultimate shear strength capacity, $V_{n}$, compared with other parameters namely, $b_{w}, f_{c}{ }^{\prime}, f_{F R P}, \rho_{F R P}$, and $E_{F R P}$.

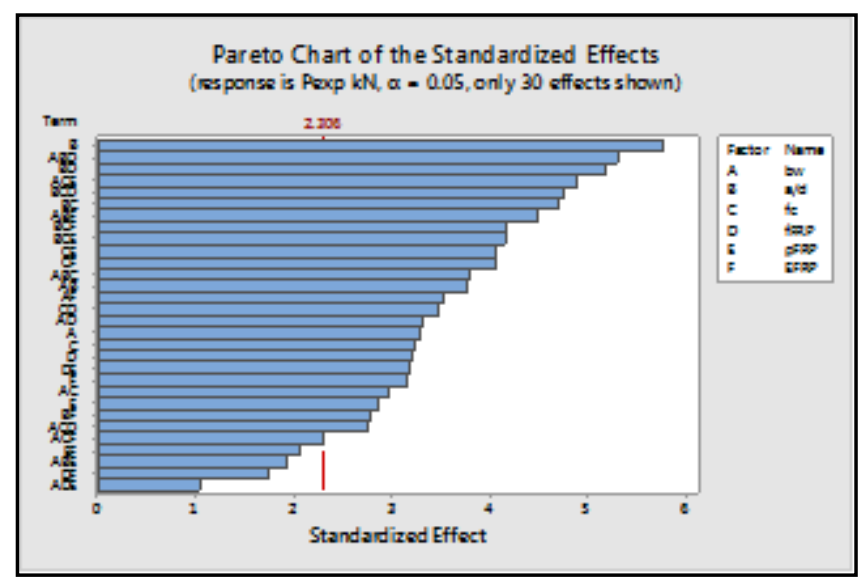

Fig. 5: Pareto chart of the ultimate shear capacity.

\section{Results and discussion}

In this section, the outcomes of the proposed strut effectiveness factor, $v$, is presented and discussed in terms of ultimate shear strength capacity, $V_{n}$.

\subsection{Verification of the proposed model}

In view of a legitimate speculation (Smith, 1986), when the connection coefficient of a model is more than 0.8 , i.e. $\mathrm{R}>0.8$, a solid straight connection between the anticipated and estimated qualities can be normal. Fig. 6 shows a correlation of the exploratory and the anticipated extreme shear quality qualities. The figure shows a solid association with a relationship coefficient, $\mathrm{R}$, in the scope of 0.9259 .
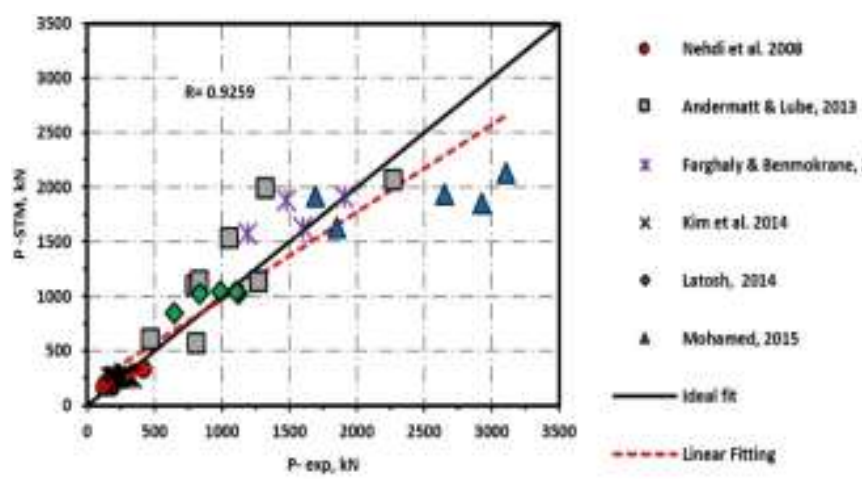

Fig. 6: Experimental versus predicted ultimate shear strength.

\subsection{Model validity}

Notwithstanding the conventional relationship coefficient, R, numerous other criteria have been proposed by (Golbraikh and Tropsha, 2002) to guarantee confirmation of the proposed model on the datasets. They proposed that something like one slant of relapse lines ( $\mathrm{k}$ or $\left.\mathrm{k}^{\prime}\right)$ through the beginning ought to be near 1 (Gandomi and Alavi, 2013). Moreover, (Roy and Roy, 2008) presented an affirming marker of the outside consistency of models ,R_m. For R_m >0.5, the condition is viewed as acceptable. The approval criteria with the appropriate outcomes decided from the proposed model are abridged in Table 3. This Table demonstrates that the proposed model fulfills the required conditions.

Table 3: Statistical parameters of the proposed model for external validation.

\begin{tabular}{|c|c|c|c|}
\hline $\begin{array}{l}\text { Ite } \\
\mathrm{m}\end{array}$ & Formula & $\begin{array}{l}\text { Condi- } \\
\text { tion }\end{array}$ & $\begin{array}{c}\text { Pro- } \\
\text { posed } \\
\text { STM } \\
\end{array}$ \\
\hline 1 & $\begin{array}{l}R \\
=\quad \sum_{i=1}^{n}\left(E A_{i}-\overline{E A_{l}}\right)\left(E E_{i}-\overline{E E_{l}}\right)\end{array}$ & $R>0.8$ & 0.9259 \\
\hline & $\sqrt{\sum_{i=1}^{n}\left(E A_{i}-\overline{E A_{l}}\right)^{2}} \sum_{i=1}^{n}\left(E E_{i}-\overline{E E_{l}}\right)^{2}$ & & \\
\hline 2 & $k=\frac{\sum_{i=1}^{n}\left(E A_{i} \times E E_{i}\right)}{E A_{i}^{2}}$ & $\begin{array}{l}0.85<k \\
<1.15\end{array}$ & 0.9018 \\
\hline 3 & $k^{\prime}=\frac{\sum_{i=1}^{n}\left(E A_{i} \times E E_{i}\right)}{E E_{i}^{2}}$ & $\begin{array}{l}0.85 \\
<k^{\prime} \\
<1.15\end{array}$ & 1.0321 \\
\hline 4 & $\begin{array}{l}R_{m}=R^{2} \times\left(1-\sqrt{\left|R^{2}-R_{o}^{2}\right|}\right) \\
\text { where } \\
\begin{array}{r}R_{o}^{2}=1-\frac{\sum_{i=1}^{n}\left(E E_{i}-E A_{i}^{o}\right)^{2}}{\left(E E_{i}-\overline{E E_{l}}\right)^{2}}, E A_{i}^{o} \\
=k \times E E_{i}\end{array}\end{array}$ & $\begin{array}{l}R_{m} \\
>0.5\end{array}$ & 0.5611 \\
\hline
\end{tabular}

\subsection{Error evaluation}

Sometimes, the correlation coefficient, $R$, is not a suitable indicator for an accurate prediction, as it does not respond to the changes due to multiplication or addition by a constant in the output values. Thus, to assess the model powerful, an error approach should be utilized in conjunction with the $R$ values. (Gandomi, Alavi, Mousavi, \& Tabatabaei, 2011) proposed a performance evaluation function by considering the changes in correlation and error functions. Performance index, $P I$, was used based on the function to evaluate performance as a function of the correlation coefficient, $R$, and relative root mean square error, RRMSE, and as follows:

$P I=\frac{R R M S E}{R+1}$

$R R M S E=\frac{1}{\left|\overline{E A}_{i}\right|} \sqrt{\frac{\sum_{i=1}^{n}\left(E A_{i}-E E_{i}\right)^{2}}{n}}$

$R=\frac{\sum_{i=1}^{n}\left(E A_{i}-\overline{E A}\right)\left(E E_{i}-\overline{E E}\right)}{\sqrt{\sum_{i=1}^{n}\left(E A_{i}-\overline{E A}\right)^{2} \sum_{i=1}^{n}\left(E E_{i}-\overline{E E}\right)^{2}}}$

where [EA】_i and [EE \_i are the ith test and anticipated yields, individually; (EA) ${ }^{-}$and (EE) ${ }^{-}$speaks to the normal estimations of the exploratory and anticipated yields, separately while $n$ signifies the quantity of tests.

High R esteems with low RRMSE values result in lower PI to show a more precise model. It's helpful to take note of that PI esteems go from 0 to $+\infty$, with littler qualities indicating better execution and it is the suggested acknowledgment limit.

The generally speaking measurable execution of the proposed model is displayed in Table 4 that demonstrates a high R-esteem and the best (the most reduced) relative root mean square mistake, RRMSE, esteem. It ought to be noticed that as indicated by the measurable criteria, the proposed model has a decent relationship and covariance and in addition a satisfactory estimation of PI.

In addition, (Bagheri, Bagheri, Gandomi, and Golbraikh, 2012) prescribed that expectation capacities of the model must be resolved dependent on the relative mistake appropriation. Subse- 
quently, without a doubt the, relative mistake, ARE, the rate is accounted as:

$A R E=\left|\frac{E A_{i}-E E_{i}}{E A_{i}}\right| \times 100$

Figure 7 demonstrates the ARE distribution for the proposed model. Typically, the frequency presented in the figure have to decrease with an increase in ARE. The proposed model has the highest frequencies of low ARE (ARE <10\%). Thus, the proposed model has an acceptable error distribution and it can be used safely.

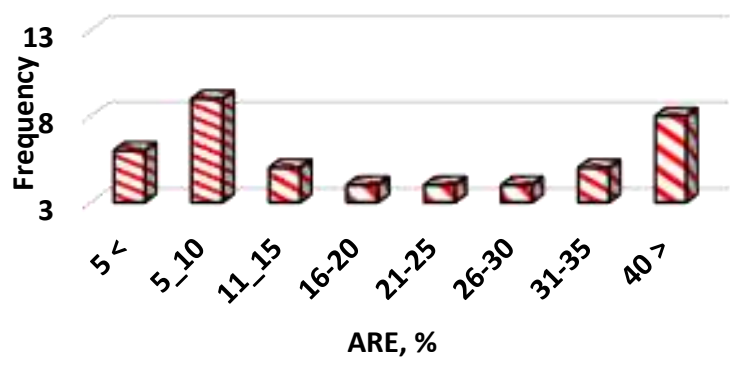

Fig. 7: Absolute, relative error (ARE) distribution of the proposed model.

Table 4: Overall performances of the models for the energy absorption capacity prediction of $\mathrm{RC}$ beams

\begin{tabular}{lccc}
\hline Model & \multicolumn{3}{c}{ Experimental vs predicted } \\
\cline { 2 - 4 } & RRMSE $(\%)$ & $R$ & $P I$ \\
\hline Proposed model & 0.6713 & 0.9259 & 0.3485 \\
\hline
\end{tabular}

\section{Conclusions}

A simple strut effectiveness factor model is proposed to evaluate for the influence of FRP bars as reinforcement in concrete deep beams on the ultimate shear strength. The proposed model is evaluated using a total of 45 test results collected from the literature. The main conclusions of this study are illustrated in the following main points:

The results display that the proposed model produces safe and appropriate estimates for FRP-reinforced concrete deep beams with various beam geometrical limitations, flexural reinforcement ratios, and shear reinforcement ratios.

Based on a correlation coefficient, $\mathrm{R}$, in the range of 0.9259 , the statistical analysis shows good accuracy and consistency for the FRP-reinforcing concrete deep beams.

The proposed model can be utilized to account the ultimate shear capacity of concrete deep beams reinforced with FRP bars.

Several assumptions have been adopted through the derivation of the model, such as linear stress distribution, and the stress distribution factors. These assumptions were adopted to simplify the model without any loss in the accuracy of the results, as indicated. The results displayed that the shear span to effective depth ratio has the highest important effect on the ultimate shear strength of FRP-reinforced concrete deep beams with bars.Summary points:

Lack of information has been recorded for estimating the ultimate shear strength of RC deep beams reinforced with FRP bars.

For further accurate outcomes, more research is needed to develop the strut effectiveness factor model through considering the nonlinear stress distribution effect.

A shear tension Failure that caused by an insufficient anchorage of flexural FRP-reinforcement to be considered in future studies.

\section{References}

[1] Bagheri, M., Bagheri, M., Gandomi, A. H., \& Golbraikh, A. (2012). Simple yet accurate prediction method for sublimation enthalpies of organic contaminants using their molecular structure. Thermochimica acta, 543, 96-106.

[2] Cook, R. D., \& Young, W. C. (1999). Advanced mechanics of materials (Vol. 2): Prentice Hall Upper Saddle River, NJ.

[3] CSA-S806-02. (2004). Design of Concrete Structures, Canadian Standards Association: Mississauga, Ont.: Canadian Standard Association.

[4] Duthinh, D. (1999). Sensitivity of shear strength of reinforced concrete and prestressed concrete beams to shear friction and concrete softening according to modified compression field theory. ACI Structural Journal, 96(4).

[5] Foster, S. J. (1992). The structural behaviour of reinforced concrete deep beams. University of New South Wales.

[6] Foster, S. J., \& Malik, A. R. (2002). Evaluation of efficiency factor models used in strut-and-tie modeling of nonflexural members. Journal of Structural Engineering, 128(5), 569-577. doi: DOI: 10.1061/(ASCE)0733-9445(2002)128:5(569)

[7] Gandomi, A. H., \& Alavi, A. H. (2013). Expression programming techniques for formulation of structural engineering systems (Vol. 18): chapter.

[8] Gandomi, A. H., Alavi, A. H., Mousavi, M., \& Tabatabaei, S. M. (2011). A hybrid computational approach to derive new groundmotion prediction equations. Engineering Applications of Artificial Intelligence, 24(4), 717-732.

[9] Golbraikh, A., \& Tropsha, A. (2002). Beware of q 2! Journal of Molecular Graphics and Modelling, 20(4), 269-276.

[10] Kupfer, H., Hilsdorf, K., \& Rush, H. (1973). Behavior of concrete under biaxial stresses.

[11] Roy, P. P., \& Roy, K. (2008). On some aspects of variable selection for partial least squares regression models. QSAR \& Combinatorial Science, 27(3), 302-313.

[12] Tan, K., Tong, K., \& Tang, C. (2001). Direct strut-and-tie model for prestressed deep beams. Journal of Structural Engineering, 127(9), 1076-1084

[13] Tanapornraweekit, G., Haritos, N., \& Mendis, P. (2010). Behavior of FRP-RC Slabs under Multiple Independent Air Blasts. Journal of Performance of Constructed Facilities, 25(5), 433-440.

[14] Tong, K. (1997). Strut-and-Tie Approach to Shear Strength Prediction of Deep Beams (MEng Thesis). Singapore: Nanyang Technological University.

[15] Vecchio, F. J., \& Collins, M. P. (1986). The modified compressionfield theory for reinforced concrete elements subjected to shear. Paper presented at the ACI Journal Proceedings. 